\title{
Plan spawania ciśnieniowego zespołu rurowego
}

\section{Welding plan of pressure pipe set}

\section{Streszczenie}

W artykule podjęto próbę zdefiniowania terminu „plan spawania". Przeanalizowano potrzebę stosowania planu spawania, jego formę, zakres oraz znaczenie dla wytwórcy. Przedstawiono też praktyczny przykład planu dla ciśnieniowego zespołu rurowego.

\section{Abstract}

In the article the authors tool an attempt to define the term "welding plan". The need for using welding plan, its form, range and importance for the producer were analyzed. The practical welding plan was presented for the pressure pipe set.

\section{Wstęp}

Plan spawania - temat pozornie oczywisty, specjalista powie wręcz banalny. Jednak, gdy zaczniemy się zastanawiać głębiej, okazuje się, iż nie jest to temat tak jednoznaczny i prosty. Co więcej, można podchodzić do niego w różny sposób i różnie go definiować. Przykłady planów spawania dla różnych wyrobów przedstawiono w pracach $[1 \div 10]$.

\section{Definicja i znaczenie}

Najpierw rozważmy samo słowo plan, które słownikowo ma kilka, zresztą powszechnie znanych znaczeń. Dla naszych potrzeb plan to:

- coś, co zamierzamy zrobić, wykonać; lub dokładniej

- układ zadań i prac, zazwyczaj w postaci diagramu, wykazu czy tabeli, przewidzianych do realizacji i uzgodnionych czasowo.

Mgr inż. Dariusz Chromik - PGNiG Technologie, Oddział GAZOBUDOWA, Zabrze, dr hab. inż. Jacek Słania, Prof. IS - Instytut Spawalnictwa, Gliwice.

Gdy do powyższych określeń dodamy znaczenie słowa spawanie, to będziemy mogli zaproponować definicję analizowanego terminu. Najkrócej można by powiedzieć, że: plan spawania to schemat wykonawczy/wykonania konstrukcji spawanej lub starając się definiować dokładniej: plan spawania to przedstawiony w sposób umowny zbiór działań niezbędny do wykonania konstrukcji spawanej. Jest to definicja ogólna i otwarta, a jednocześnie zwięzła i skondensowana, która nic nie narzuca wykonawcy.

$Z$ drugiej strony, sformułowanie plan spawania, mimo iż często w branży spawalniczej stosowane, nie jest zdefiniowane w żadnym dokumencie normatywnym. Nasuwają się więc pytania. Pierwsze, podstawowe, to czy plan spawania jest w ogóle potrzebny? Jeśli tak, to w jakim zakresie? Co powinien obejmować? Czy powinien być sformalizowany? A może powinien być obligatoryjny? Każdy z nas mógłby zadać wiele takich pytań. I różne by prawdopodobnie padały odpowiedzi. Spróbujmy więc przeanalizować niektóre z nasuwających się pytań i zaproponować odpowiedzi. Bazą do tych rozważań powinno być rozumienie spawania jako procesu specjalnego oraz to, że wytwarzając konstrukcję spawaną, wykonawca jest zobligowany spełnić założony w warunkach technicznych wykonania i odbioru lub w projekcie poziom jakości. Jeśli mowa o jakości, to spawalnikowi nasuwa się jednoznacznie norma 
PN-EN ISO 3834. Zarówno w Części 2: Pełne wymagania jakości, jak i w Części 3: Standardowe wymagania jakości, określono wymagania dotyczące spawania materiałów metalowych zarówno w wydziałach produkcyjnych, jak i instalacjach na budowie w sposób kompleksowy. Dokładnie i szczegółowo wytyczono tok postępowania, zaczynając od przeglądu wymagań, a kończąc na zapisach jakości, by mieć pewność, że wytwarzana konstrukcja spawana spełni narzucone jej wymagania jakościowe. W normie PN-EN ISO 3834-2 p. 10: Spawanie i działalność związana zawiera p. 10.1 zatytułowany Planowanie produkcji. Określa on konieczność wykonania przez wytwórcę planu produkcji. Plan ten jest uszczegółowiony przez autorów normy dziesięcioma odnośnikami, wskazującymi minimalną ilość i rodzaj informacji, jakie powinien zawierać taki plan. Należy powtórzyć, że jest tu określony plan produkcji, a nie plan spawania. Termin plan produkcji pojawia się również w p. 17 normy: Identyfikacja i identyfikalność oraz w p. 18: Zapisy jakości. Natomiast nigdzie $w$ treści normy nie pojawia się analizowane przez nas pojęcie planu spawania. A więc jeśli w spawalniczej normie-matce, normie-przewodniku jaką jest PN-EN ISO 3834, nie istnieje plan spawania, to może znaczy to, iż nie ma potrzeby zajmowania się tym tematem, że plan spawania to może wręcz coś niepotrzebnego? W żadnym wypadku nie powinno się wysnuwać takich wniosków. Plan produkcji, używany w PN-EN ISO 3834, należy po prostu rozumieć szerzej. I dlatego autorzy normy, definiując plan, użyli słowa produkcji, a nie spawania, bo spawanie to przecież pewna część procesu produkcyjnego, choć bardzo istotna, ale tylko część. Natomiast plan spawania to spawalniczy konkret. To przedstawione w pewnym schemacie/porządku wszystkie istotne aspekty procesu, którego wynikiem jest konstrukcja spawana, wykonana zgodnie $z$ wymaganiami. To coś, co ma pomóc wytwórcy w wykonawstwie. Zabezpieczyć go przed popełnieniem jakiegoś, nawet przypadkowego błędu, którego czasami nie da się już naprawić. Dlatego na podstawowe pytanie, czy plan spawania jest potrzebny - odpowiedź byłaby na pewno twierdząca. Ale tu od razu uwaga - czy on jest, jaką ma formę, jakie szczegóły zawiera, powinno zależeć od konkretnego wykonawcy, jego doświadczeń i rodzaju wytwarzanych konstrukcji. Dlatego plan spawania nie może być sformalizowany, czy w jakiś sposób znormalizowany. Przecież taki plan inaczej będzie wyglądał dla produkcji seryjnej i jednostkowej, inaczej dla spawania zrobotyzowanego i ręcznego, czy też dla wytwarzania skomplikowanych, odpowiedzialnych konstrukcji i prostych elementów spawanych, gdzie na inne aspekty należy położyć nacisk, zatem różny będzie zakres poszczególnych planów. Plan spawania powinien być dostosowany do realnych potrzeb i wymagań.

Należy mieć na uwadze, że wymagania dotyczące planów spawania mogą czasem bezpośrednio wynikać z norm lub warunków technicznych wykonania i odbioru. Mogą też być określone specyficzne wymagania przez nadzory inspekcyjne.

\section{Plan spawania ciśnieniowego zespołu rurowego}

Jest to zespół zaporowo-upustowy (ZZU) DN300/ DN150, ciśnienie nominalne PN 6,3 MPa (schemat - rys.). Zastosowanie - przesył gazu ziemnego. Jest to stosunkowo niewielki i prosty układ, stanowiący część większej instalacji gazowej. Umożliwia jednak przedstawienie wszystkich aspektów pojawiających się przy realizacji podobnych konstrukcji. Plan spawania opracowuje się na podstawie zweryfikowanej przez służby spawalnicze wykonawcy dokumentacji technicznej warunków technicznych wykonania i odbioru (WTWiO) $\mathrm{i} /$ lub projektu. Warunki, które powinny być spełnione, by odpowiednio zaplanować, a następnie zrealizować prace spawalnicze na analizowanym ZZU, są następujące:

1. Wszystkie materiały podstawowe (rury, kształtki) zostały sprawdzone przez Kontrolę Jakości (sprawdzenie stanu, wymiarów) i mają odpowiednie świadectwa odbioru - z reguły 3.1, a czasem 3.2. W przypadku przecinania materiałów, oznaczenia wybite przez wytwórcę mogą być przenoszone wyłącznie przez osoby do tego upoważnione.

2. Materiały dodatkowe do spawania - pręty do metody 141 i elektrody otulone do metody 111 są zgodne z materiałami przewidzianymi w instrukcjach WPS i mają wymagane dokumenty kontroli.

3. Spawacze posiadają ważne świadectwa egzaminu zgodne z PN-EN 287-1 w wymaganym zakresie.

4. Wytwórca dysponuje wykwalifikowanym nadzorem spawalniczym.

5. Wytwórca dysponuje kwalifikowanymi instrukcjami technologicznymi spawania WPS w wymaganym zakresie prac.

6. Uzgodniono wykonawstwo i zakres badań nieniszczących.

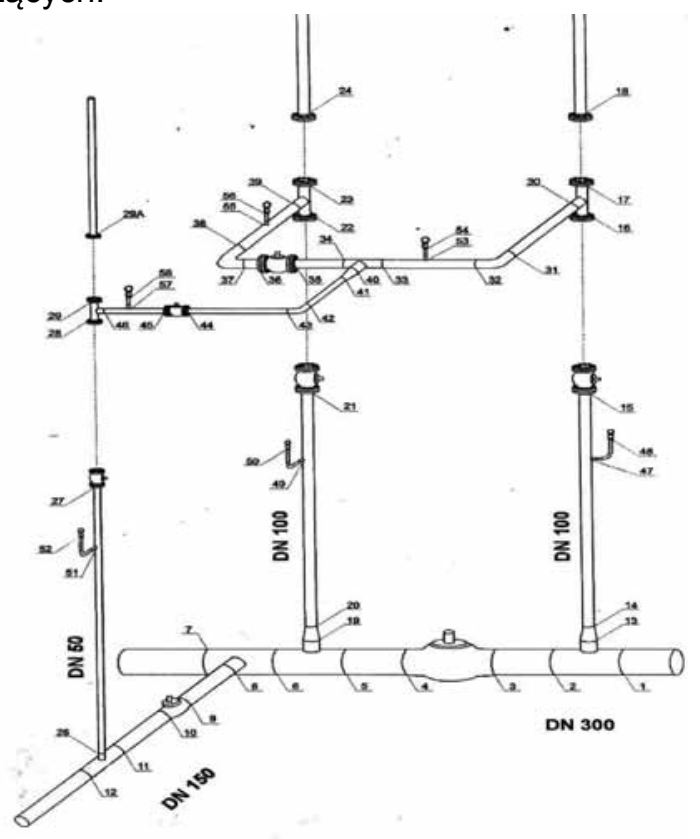

Rys. Schemat aksonometryczny zespołu

Fig. Axonometric scheme of set 


\begin{tabular}{|c|c|c|c|c|c|c|c|c|c|c|c|c|c|}
\hline \multicolumn{14}{|c|}{$\begin{array}{c}\text { PLAN SPAWANIA I BADAŃ } \\
\text { ZESPÓŁ ZAPOROWO - UPUSTOWY DN300 / DN150 PN 6,3 MPa }\end{array}$} \\
\hline \multirow{2}{*}{ Lp. } & \multicolumn{5}{|c|}{$\begin{array}{l}\text { Charakterystyka spoin } \\
\text { M1 - spoiny montażowe (prefabrykacja warsztatowa) } \\
\text { G1 - spoiny o grubości } t \geq 8 \mathrm{~mm} \text { niepodlegające ciśnieniowej } \\
\text { próbie wytrzymałości }\end{array}$} & \multicolumn{7}{|c|}{$\begin{array}{l}\text { Badania } \\
\text { W przypadku wymaganych instrukcji wpisać nr instrukcji } \\
\text { badań }\end{array}$} & \multirow{2}{*}{ Nr WPS } \\
\hline & $\begin{array}{l}\text { Średnica } \\
\mathrm{mm}\end{array}$ & $\begin{array}{c}\text { Grubość } \\
\mathrm{mm}\end{array}$ & $\begin{array}{l}\text { Rodzaj/ } \\
\text { numer } \\
\text { spoiny* }\end{array}$ & Element & Materiał & VT & RT & UT & MT & PT & $\begin{array}{l}\text { Próba } \\
\text { wytrzymałości* }\end{array}$ & $\begin{array}{l}\text { Próba } \\
\text { szczelności* }\end{array}$ & \\
\hline 1 & 21,$3 ; 26,9$ & 3,$2 ; 3,6$ & M1 & $\begin{array}{l}\text { rura-rura, } \\
\text { kolano, } \\
\text { kołnierz } \\
\text { szyjkowy }\end{array}$ & $\begin{array}{l}\text { L360NB; } \\
\text { P355NH; } \\
\text { P355NL1 }\end{array}$ & $X$ & $X$ & & & & & & 32/T/01 \\
\hline 2 & 21,$3 ; 26,9$ & 3,$2 ; 3,6$ & M1 & rura-rura & L360NB & $X$ & & & $X$ & $X$ & & & 32/T/02 \\
\hline 3 & 60,$3 ; 114,3$ & $\begin{array}{l}4,5 ; 5,0 \\
\quad 6,3\end{array}$ & M1, G1 & $\begin{array}{l}\text { rura-rura, } \\
\text { zwężka, } \\
\text { kołnierz, } \\
\text { trójnik, } \\
\text { kolano }\end{array}$ & $\begin{array}{l}\text { L360NB; } \\
\text { P355NH }\end{array}$ & $X$ & $X$ & & & & & & 08/T/02 \\
\hline 4 & $\begin{array}{l}168,3 \\
323,9\end{array}$ & $\begin{array}{l}6,3 ; 7,1 ; \\
8,0 ; 12,5\end{array}$ & M1, G1 & $\begin{array}{l}\text { rura-rura, } \\
\text { zawór, } \\
\text { trójnik, } \\
\text { zwężka, } \\
\text { denko, } \\
\text { monoblok }\end{array}$ & $\begin{array}{l}\text { L415NB; } \\
\text { L360NB; } \\
\text { P355NL1; } \\
\text { P355NH }\end{array}$ & $X$ & $X$ & * & & & & & 03/TE/01 \\
\hline 5 & $\begin{array}{l}168,3 \\
323,9\end{array}$ & $\begin{array}{l}6,3 ; 7,1 ; \\
8,0 ; 12,5\end{array}$ & M1, G1 & $\begin{array}{l}\text { rura-rura, } \\
\text { zawór, } \\
\text { trójnik, } \\
\text { zwężka, } \\
\text { denko, } \\
\text { monoblok }\end{array}$ & $\begin{array}{l}\text { L415NB; } \\
\text { L360NB; } \\
\text { P355NL1; } \\
\text { P355NH }\end{array}$ & $X$ & $X$ & * & & & & & 03/TE/R \\
\hline \multicolumn{14}{|c|}{$\begin{array}{l}\text { *UWAGA: } \\
\text { 1. Spoiny oznaczane zgodnie z „Instrukcją oznakowania spoin”. } \\
\text { 2. Spoiny o grubości } t \geq 8 \mathrm{~mm} \text { niepodlegające ciśnieniowej próbie wytrzymałości, której podlegają wszystkie pozostałe spoiny danego obiektu } \\
\text { lub jego fragmentu, sprawdzać dodatkowo metodą UT. } \\
\text { 3. Próby wytrzymałości i szczelności zostaną przeprowadzone zgodnie z przedstawionym „ Projektem prób”. }\end{array}$} \\
\hline
\end{tabular}

$\mathrm{Na}$ podstawie analizy dokumentacji i przedstawionych warunków można stworzyć plan spawania, który rozumiany jest jako schemat działań, w tym przypadku ujęty $w$ formie tabelarycznej i zatytułowany: Plan spawania i badań (tabl.).

Słowo badań znalazło się w tytule tablicy, by podkreślić rolę i znaczenie badań nieniszczących przy wytwarzaniu zespołów ciśnieniowych. Plan wyszczególnia, jakie elementy spawamy, podaje ich wymiary, gatunek materiału, określa rodzaj spoiny i przede wszystkim pokazuje, zgodnie z którym WPS wykonuje się daną spoinę. Plan określa też, jaką metodą NDT przeprowadza się badania poszczególnych spoin. Niezbędnym uzupełnieniem planu jest schemat aksonometryczny zespołu z zaznaczonymi spoinami (rys. 1).

W Planie spawania i badań mamy też przywołane dodatkowe dokumenty. Są to:

- Instrukcja oznakowania spoin - określająca sposób oznakowania i numeracji spoin dla całej instalacji gazowej - dany zespół zaporowo-upustowy jest tylko jej częścią. Powinna też uwzględniać wszystkie możliwe sytuacje, np. spoiny naprawiane czy też spoiny wycięte i wykonane na nowo. $Z$ reguły przyjmuje się oznaczenia literowo-cyfrowe i przykładowo spoina ZU/10R to 10 spoina na zespole zaporowo-upustowym (ZU) po naprawie (R).

- Projekt prób, który określa w sposób szczegółowy wykonanie ciśnieniowej próby wytrzymałości i szczelności na danej instalacji, uwzględniając jej specyfikę, możliwości podziału na odcinki próbne, czasem też specyficzne parametry próby, które mogą być inne niż przyjmowane standardowo, czyli np. dla próby wytrzymałości: ciśnienie próby $p=1,5 p_{\text {nom }}$ i czas $t=30$ min. Do Planu spawania i badań powinno się również dołączyć listę spawaczy z ich uprawnieniami i znakami. Wykonawca ma wówczas pełną informację o zadaniu i może przystąpić do jego realizacji. 


\section{Podsumowanie}

Plan spawania nie jest terminem jednoznacznym, można go różnie definiować. Jego forma i zawartość zależy od wielu czynników. Plan powinien być dostosowany do realnych potrzeb i wymagań.
Dla wytwórcy jest jednak istotnym narzędziem, które pozwala odpowiednio przygotować się do realizacji zadania i ustrzec przed błędami.

\section{Literatura}

[1] Słania J.: Plan spawania carg płaszcza pieca obrotowego. Przegląd Spawalnictwa 2011, nr 2, s. 36-41.

[2] Słania J., Wodecki D.: Plan spawania belki poprzecznej dźwigu. Przeglaad Spawalnictwa 2011, nr 2, s. 30-35.

[3] Słania J.: Plan technologiczny spawania płyty gąsienicowej. Przeglad Spawalnictwa 2010, nr 3, s. 16-25.

[4] Słania J., Kwiecień L., Jarosiński J.: Plan spawania kotłów płomienicowo-płomieniówkowych. Przegląd Spawalnictwa 2010 nr 6, s. 32-40.

[5] Słania J., Skóra J.: Plan spawania wymiennika ciepła chłodzonego powietrzem. Przegląd Spawalnictwa 2011, nr 2, s. $16-22$.
[6] Słania J., Urbańczyk P.: Technologia wytwarzania oraz plan kontroli jakości gazoszczelnych ścian rurowych kotła pyłowego wytwarzanego w oparciu o normę PN-EN 12952-5. Przegląd Spawalnictwa 2009, nr 12, s. 19-27.

[7] Słania J. Kaczor T.: Plan spawania zbiornika ciśnieniowego. Przeglad Spawalnictwa 2010, nr 4, s. 9-18.

[8] Słania J.: Plan spawania przy wykonywaniu napraw bieżących kotłów parowych, kotłów wodnych i stałych zbiorników ciśnieniowych. Przegląd Spawalnictwa 2011, nr 2, s. 22-30.

[9] Słania J.: Istota planów spawania. Przegląd Spawalnictwa 2011, nr 2, s. 3-9.

[10] Norma PN-EN ISO 3834-2 Wymagania jakości dotyczące spawania materiałów metalowych. Cz. 2: Pełne wymagania jakości.

\section{Wydarzenia}

\section{Szkoła Inżynierii Materiałowej 24-27.09.2012, Kraków}

W dniach 24-27 września 2012 r. w Krakowie odbyła się XL Szkoła Inżynierii Materiałowej, której organizatorem jest Akademia Górniczo-Hutnicza im. Stanisława Staszica w Krakowie. Jest to wyjątkowe spotkanie skierowane do młodych naukowców - doktorantów, asystentów, studentów, ale i adiunktów. Wszyscy Oni zasiadają wraz z Profesorami do wspólnej dyskusji wyników badań. Spotkanie ma charakter cykliczny, dzięki czemu możliwe jest nawiązanie kontaktów, współpracy pomiędzy uczelniami i ich pracownikami zajmującymi się szeroko pojętą nauką o materiałach. We wcześniejszych latach sesje były ogólne, natomiast ostatnio ze względu na różnorodność tematów wprowadzono sesje tematyczne, które $w$ tym roku były następujące: stopy na osnowie żelaza, stopy metali nieżelaznych, inżynieria powierzchni, inżynieria spajania, utlenianie i korozja, materiały ceramiczne, kompozyty i polimery, metody komputerowe $w$ inżynierii materiałowej, odkształcanie i obróbka plastyczna oraz materiały funkcjonalne. Na szczególną uwagę zasługuje fakt,

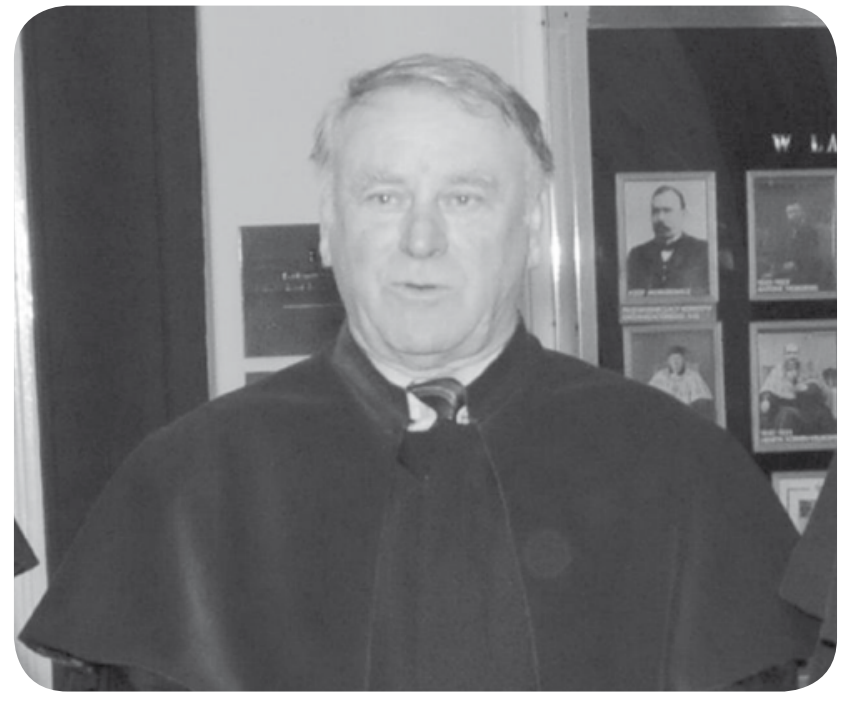

Prof. dr hab. inż. Edmund Tasak - Honorowy Profesor Szkoły Inżynierii Materiałowej 